\title{
Renal denervation as a treatment strategy for vasospastic angina induced ventricular tachycardia
}

\author{
L. Feyz ${ }^{1} \cdot$ S. Wijchers ${ }^{1} \cdot$ J. Daemen ${ }^{1}$
}

Published online: 12 June 2017

(c) The Author(s) 2017. This article is an open access publication.

Polymorphic ventricular tachycardia can be a detrimental consequence of coronary vasospasm [1]. The pathophysiology of vasospastic angina (VA) is poorly understood, although the disease has been linked to sympathetic hyperactivity [2-4]. We present a 52-year-old male smoker with ventricular fibrillation (VF) 2 years ago. Work-up revealed no signs of structural heart disease or obstructive coronary disease. We implanted an implantable cardioverter defibrillator (ICD). Several episodes of non-sustained polymorphic ventricular tachycardia and ICD shocks due to VF ensued, despite maintenance therapy with isosorbide $100 \mathrm{mg}$, metoprolol $50 \mathrm{mg}$, verapamil $300 \mathrm{mg}$, amiodarone $200 \mathrm{mg}$. Methylergometrine testing confirmed VA as the cause of VF (Fig. 1a,b). To reduce sympathetic hyperactivity, bi-

Fig. 1 Methylergometrine testing revealed severe coronary spasms in multiple coronary segments resulting in ventricular tachycardia and haemodynamic collapse (a). This quickly resolved after intracoronary nitrates $(\mathbf{b})$
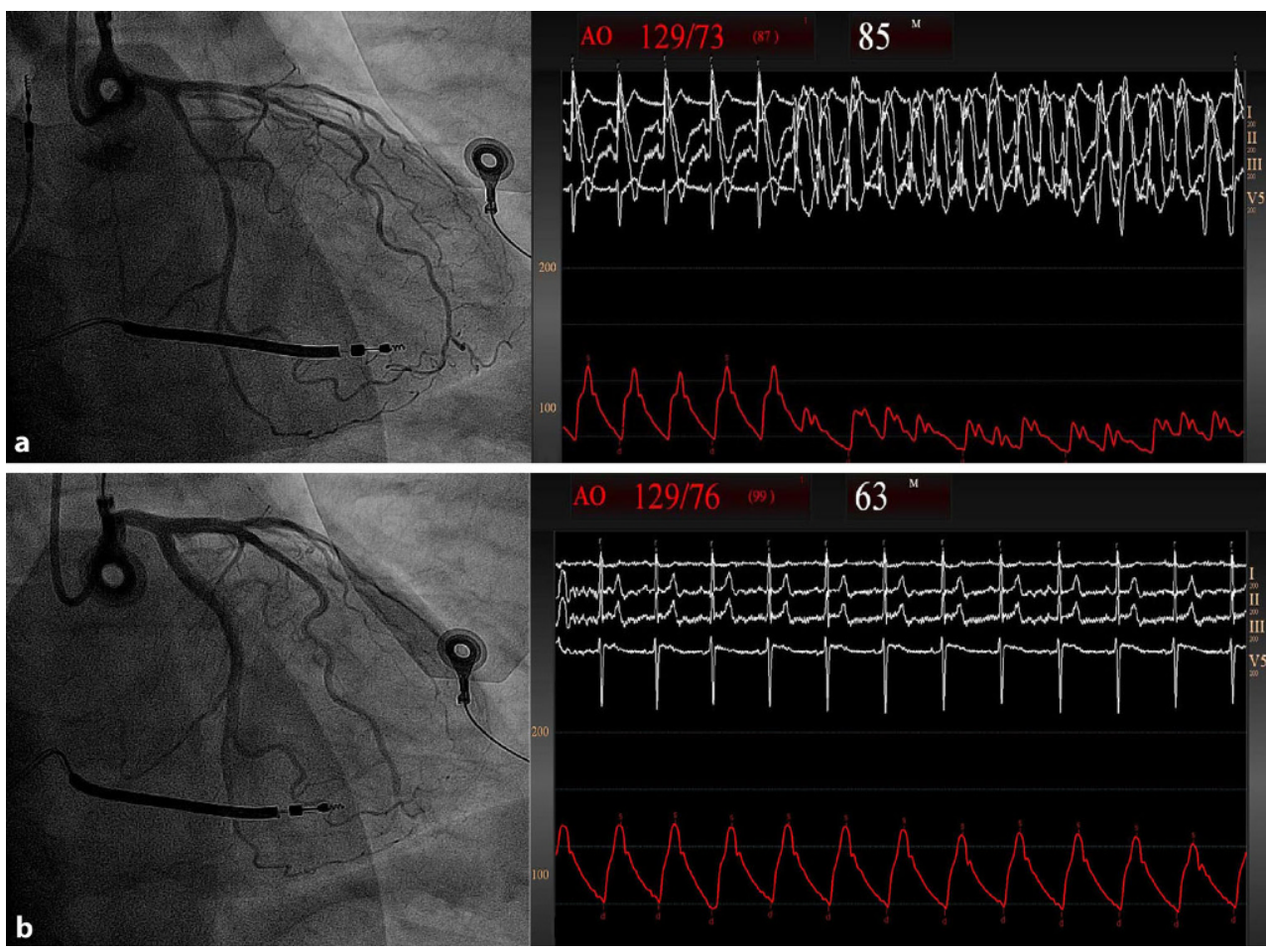

J. Daemen

j.daemen@erasmusmc.nl

1 Department of Cardiology, Thorax Center, Erasmus Medical Center, Rotterdam, The Netherlands 
lateral renal denervation was performed using the ReCor Paradise system. The patient remained free from episodes of angina and ventricular arrhythmias at 6 and 12 months. Ambulatory blood pressure and mean heart rate remained stable between baseline and 6 months $(108 / 60 \mathrm{~mm} \mathrm{Hg}$ vs. $113 / 71 \mathrm{~mm} \mathrm{Hg}$ and $60 \mathrm{bpm}$ vs. $60 \mathrm{bpm}$, respectively). Renal denervation could be a safe and effective treatment for normotensive patients with severe VA despite optimal medical therapy.

Conflict of interest L. Feyz, S. Wijchers and J. Daemen declare that they have no competing interests. The Erasmus Medical Center received institutional research support from Boston Scientific, St. Jude Medical, Medtronic, ReCor Medical, Acist Medical.

Open Access This article is distributed under the terms of the Creative Commons Attribution 4.0 International License (http:// creativecommons.org/licenses/by/4.0/), which permits unrestricted use, distribution, and reproduction in any medium, provided you give appropriate credit to the original author(s) and the source, provide a link to the Creative Commons license, and indicate if changes were made.

\section{References}

1. Dhawan SS, Shirwany A. Vasospasm-induced polymorphic ventricular tachycardia. Can J Cardiol. 2008;24:e104.

2. Yasue H, Touyama M, Shimamoto M, et al. Role of autonomic nervous system in the pathogenesis of Prinzmetal's variant form of angina. Circulation. 1974;50:534-9.

3. Lombardi F, Verrier RL, Lown B. Relationship between sympathetic neural activity, coronary dynamics, and vulnerability to ventricular fibrillation during myocardial ischemia and reperfusion. Am Heart J. 1983;105:958-65.

4. Huang B, Yu L, He B, et al. Renal sympathetic denervation modulates ventricular electrophysiology and has a protective effect on ischaemia-induced ventricular arrhythmia. Exp Physiol. 2014;99:1467-77. 